\title{
Collegial teaming for inclusive education using photovoice as tool
}

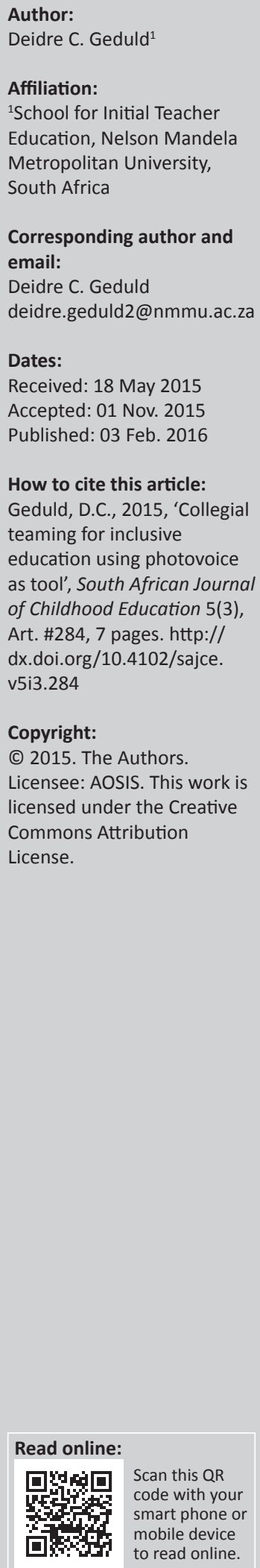

As a Foundation Phase (FP) and inclusive education (IE) lecturer I am responsible for preparing teacher education students for the diversity in classrooms in low socio-economic environments, where teachers have very little professional help in the form of health professionals and remedial and support teachers. This qualitative study explored how collegial teaming amongst pre- and inservice FP teachers can promote the practice of IE. Photovoice technology was used to explore teachers' challenges in mainstream classrooms and to investigate how teaming can promote IE practices. Participants included five practising inservice mentor teachers and five fourth-year preservice teachers from the local university. The findings have implications for an IE conception of quality, academic rigour and depth in initial teacher education focusing on school-based learning and teaching experiences. This study, with its 'research as intervention' approach, enabled collegial teams to make their voices heard and to reflect critically on what it is that they can do to contribute to promoting the practice of IE.

\section{Introduction}

I don't like inclusive education. It suggests that I take responsibility for my children's learning; whilst the classrooms are overcrowded it hinders me from reaching each individual child, but most importantly I don't have the skills to ensure that learning opportunities are created for learners with barriers to learning. (Sarah)

The above quotation by one of the teacher participants in this study captures the dilemma faced by many teachers in the implementation of inclusive education (IE) within mainstream classrooms. The Department of Basic Education (DBE 2012) reported that the IE system in South Africa is not functioning effectively in its progress report on the implementation of White Paper 6 (20012012) and emphasised that IE should strengthen interdepartmental cooperation and stakeholder engagement and that guidelines should be developed for establishing a collaborative IE system. This response by the DBE motivated me to think about new approaches that can support teachers' professional learning, effectiveness and growth to implement IE within mainstream classrooms. I asked the question 'How might teacher preparation programmes and professional learning opportunities more effectively equip pre- and inservice teachers to face the IE challenges together?'. Upon reflection, I was convinced that a study could provide some answers. Upon embarking on the research, I asked another, and more directed, question: How can collegial teaming and photovoice as a tool promote the practice of IE in the foundation phase (FP)? The aim of this study was to create and then research collegial teaming amongst FP pre- and inservice teachers, for developing and strengthening the practice of IE. As teachers, we know that education may perpetuate social inequalities and injustice with regard to marginalising and excluding groups of learners across a range of abilities, characteristics, developmental trajectories and socio-economic circumstances. Freire $(1973,1992,2000)$ proposed that education should help teachers to achieve a critical understanding of their own reality and engage in transformative actions for social change. By critical understanding, Freire referred to a deep examination, through dialogue with others. Therefore, in designing this study, I planned for collegial teaming, which offered the possibility that participants could create inclusive educational experiences that find common ground for each unique constellation of learners and support their learning trajectories. For this purpose, I discuss two core issues: IE for all and theoretical framing: collegial teaming.

\section{IE for all}

Regardless of the gains made, since the dawn of democracy in 1994, South Africa continues to face significant challenges in poverty, unemployment and unequal access to resources and education. These problems are also at the root of many of the current challenges facing the education of children and teachers, in particular within the IE framework. The bulk of IE has neglected 
fundamental questions about the political economy analysis of education and its link to larger ideological struggles that have shaped differential access and opportunities for various groups in the society. These questions include the following: Who benefits from inclusion? Where are these learners included? What are the consequences of who benefits and where inclusion is enacted?

Although a sizeable amount of scholarship has been produced on IE, it has ignored the fact that poor black learners are overrepresented in our identification of learners who experience barriers to learning (Artiles 2003). This is not an accidental omission, because most of the research in this (and other related) field(s) is colour-blind (Arzubiaga et al. 2008). For instance, Sheehy et al. (2009) highlight that inequalities in a society, the lack of access to basic services and poverty are factors that place children at risk.

Evidence (Ruijs, Van der Veen \& Peetsma 2010) suggests that who is identified as experiencing barriers to learning is related to restrictiveness of ability to teach these learners within mainstream classrooms and access to related services, interventions and programmes. Engelbrecht and Green (2007) emphasise that it is necessary to embrace a systemic paradigm in which the structures and functioning of the education system are called into question. In South Africa, inequalities resulting from apartheid and economic deprivation have had a great impact on the education system and especially on those learners who face barriers to learning. The promises of IE, however, remain unfulfilled in South Africa because the existing educational systems are not designed to respond to macrostructural forces and challenges that perpetuate inequalities or to respond to diverse learners' needs (Waitoller \& Kozleski 2008).

However, Inclusion means we all belong, including teachers who have limited knowledge of and skills in IE. They are the primary resource for achieving the goal of an IE and training system (Department of Education 2001). Teachers were hardly ever prepared for these roles, nor do they have the repertoire to address the diverse needs of all their learners. Teachers should be enabled to develop skills, and confidence in themselves ought to be strengthened in their role as lifelong learners within their vocation (Engelbrecht \& Green 2007:58).

\section{Theoretical framing: Collegial teaming}

Collegiality, as defined by Shah (2011), is the cooperative relationship amongst colleagues. Kelchterman (2006) highlights that collegial relations constitute an important working condition for teachers, and as such, they influence the professional development of teachers and schools. Practising teachers need to establish collegial teams for professional development that will support their daily practice (Novak 2008). Collectively, collegial teams develop activities that are not removed from the realities of their work. Teachers need to be working with the people, issues and concerns they face daily if they are to see the need for and relevance of teacher development with IE (Robertson 2008:6). Teachers must be challenged to understand and reflect on how changing their practice will make a difference to the education of learners on the margin of effective teaching and learning. Collegial teaming provides that challenge, because participants share their perspectives with each other in a learning community. Robertson (2008:7) contends that the variety of perspectives, the development of activities and skills, and the presence of support all serve as professional development opportunities that enhance collegial teaming relationships.

Teaming is a practice, whereby more than one teacher is placed in a classroom. According to Drago-Severson (2004) research shows that collegial teaming cultivates fresh avenues for teacher collaboration; sharing responsibility for group learning and working together enhance effectiveness. Schön (1987) proposes that teaming contributes to a culture of adult learning through challenging teachers to examine their assumptions and practice. Teaming can be a developmental learning process, because it cultivates an individual's skills for dialogue and discussion, builds leadership and contributes to both personal and professional growth (Senge et al. 1994).

Ainscow (2002) states that schools are places where teachers, students and learners are engaged in activities that help them to become more successful in understanding and dealing with problems. In the context of collaborative problem solving for effective teaming, it can be seen as an opportunity for preand inservice teachers to learn, develop and become more effective. Drago-Severson (2009) highlights that the skills for effective teaming are listening, reflective interviewing, selfassessment, goal-setting, developing action plans, setting time frames, observing and describing practice and giving effective feedback. Robertson (2008) emphasises that these skills lead participants through dialogue towards praxis and are therefore an intentional bridge between theory and practice.

Teaming can also be a context for testing new ideas and action as colleagues collaborate over time (Drago-Severson 2004 , 2009). Fundamentally, teaming holds the possibility of enabling all teachers to improve their capability to handle the complex responsibilities of teaching and learning within an inclusive classroom. Schön (1987) proposes teaming, which contributes to a culture of adult learning through challenging teachers to examine their assumptions and practice.

\section{Research design and methods}

This qualitative, interpretivist and critical research study draws on the experiences of pre- and inservice teachers as they formed collegial teams (Charmaz 2006:3) to explore how they deal with the challenges of IE and how - by working in a team - they can address these. The study therefore also draws on critical educational research (Cohen, Manion \& Morrison 2007:26), because working with the participants could contribute to their changing their lived worlds in small ways, to reduce 'exclusive practises through building collegial 
teams within their classrooms' and forming 'communities of practice' (Cohen et al. 2007:26).

Participatory visual methodology embraces a range of strategies for activating research processes that are situated within the participants' space and time contexts. Blackbeard and Lindegger (2014) emphasise that these methods are participant-centred; the participant actively produces meaning-making through collaborative processes as individual participants and/or as a collegial team.

\section{Photovoice}

Photovoice, developed by Wang and Burris (1997) as a community-based participatory research technique, draws upon documentary photography, feminist theory and critical consciousness theory. The photovoice technique puts cameras into the hands of participants and empowers them to guide data collection efforts by documenting their observations about various phenomena through photography and developing narratives about the photographs (Wang \& Burris 1997:369). (In this study, the community represented would be pre- and inservice teachers who formed collegial teams.) They further state that it is a method designed to empower members of marginalised groups, as it creates opportunities for them to actively participate in enhancing their communities by giving them a chance to have their voices heard. Gamble (2006) highlights that photovoice deepens participants' understanding of a particular concept.

Building on feminist theory, photovoice challenges the established politics of representation by shifting control over the means for documenting lives from the powerful to the powerless, from the expert to the lay person, from the professional to the client, from the bureaucrat to the citizen and from the observer to the observed (Booth \& Booth 2003). It invites us to look at the world through the same lens as the photographer and to share the story that the picture evokes for the person who clicked the shutter (Booth \& Booth 2003). Wang et al. (1998) are of the opinion that it allows participants the space to share stories in their own voice whilst providing meaning and context for the images. It also enriches IE practices by ensuring participant involvement in meaningful dialogical democratic activities (Gallo 2001) to join in consciousness raising and to create social change. Cortazzi and Jin (2007) argue that articulating proposed meaning and understanding others' meanings is what drives IE practices. Thus, photovoice is a more egalitarian and inclusive method that could help minimise the power differential.
Using photovoice to engage with pertinent issues within the participants' social reality is more important than the end product, i.e. the photographs. The photovoice technique has been used in an array of research projects, ranging from working with Chinese village women (Wang, Burris \& Xiang 1996), homeless populations (Dixon \& Hadjialexiou 2005) and people with intellectual disabilities (Jurkowski 2008), to African American women who have survived breast cancer (King et al. 2005), and refuge populations (Dumbrill 2009). Photovoice is increasingly being used across the globe in research related to a variety of issues on IE and special-needs education (Booth \& Booth 2003), not to mention HIV and AIDS in South Africa (Moletsane et al. 2007).

\section{The school and the participants}

This study took place at a primary school in the northern areas of Nelson Mandela Bay Metropole in the Eastern Cape of South Africa. The northern areas of Nelson Mandela Bay Metropole are a direct result of the Group Areas Act, which was passed by the South African National Government in the early 1950s to separate the races. This brought about the formation of suburbs such as Bethelsdorp, Gelvandale and Schauderville, which were initially populated by the 'socalled' Coloured population. Today, people from different income levels, and therefore different socio-economic conditions, live there. A school in the northern areas was purposefully selected as this school has participated in various postgraduate research projects since 2007, for example a project on the implementation and management of IE in a context of low socio-economic means (Geduld 2009).

Ten participants, working in five teams of two each, were purposively selected using the following criteria: they were involved in the FP, either teaching in the FP at the school or as a fourth-year Bachelor of Education FP student teacher doing Working Integrated Learning at the school. The purpose of the teams was to provide support and opportunities for new learning to each other. In total five inservice and five fourth-year FP preservice teachers participated in the study (Table 1).

\section{Ethical considerations}

Participants were informed of the aims of the study and assured that their contributions would be treated with confidentiality. They werealsoassured that their participation in the study was voluntary and that they could withdraw at any point if they felt uncomfortable or withdraw parts of their contributions if they felt uncomfortable disclosing these to a wider public. I also sought their permission to

TABLE 1: Biographical information of the 10 participants.

\begin{tabular}{lll}
\hline Variable & Five teachers & Five student teachers \\
\hline Age range (years) & $50-62$ & $22-26$ \\
Qualifications & Teaching Diplomas & Final-year B.Ed. FP \\
Number of years in practice & $25+$ & None \\
Professional development in IE (remedial education) & None & IE and Barriers to Learning (third-year module), Remedial Education (fourth-year module) \\
Language & All Afrikaans speaking & All English speaking \\
Sex & All women & All women \\
\hline
\end{tabular}


audio-record the discussions, which were later transcribed verbatim (Patton 2002). Pseudonyms have been used to present the participants' experiences. I adhered to the ethical guidelines of relevant Departments of Education for conducting research; paramount to my research is the ethics document (Mitchell 2011; Moletsane et al. 2008), bearing in mind the need to - through visual research - foreground the voices of marginalised, sidelined or silenced FP IE teachers who work in low socio-economic contexts.

Questions that guided this process were as follows: How can the visual data generated by teams themselves be used to do 'most good' within their IE classrooms? How can the visual data be used in and by the school community to enhance professional development? How can the visual data be utilised to take action and bring about change? Who owns the data? Clearly, these are some of the issues that should be raised when considering visual ethics (Mitchell 2011).

\section{Data generation}

At the first meeting, I explained the aim of the project as being able to obtain inservice and preservice teachers to work collaboratively in teams towards strengthening IE practices in the classroom. I explained the concept of teaming to the participants, and they collectively decided that they will be refered to as 'collegial teams' instead of groups. The five teams met at the school weekly, on a Friday afternoon, to plan and project their thinking around how to create learning opportunities for learners with barriers to learning in the individual classrooms. During this meeting time, they shared their planning for the coming week and what they could do to create learning opportunities for all learners within their classrooms. The data were generated in three phases, as outlined below.

\section{Phase one}

In planning for the workshop, I drew on the work of De Lange, Mitchell and Stuart (2007). Participants were introduced to photovoice to explain and familiarise them with the process. Thereafter, participants were each asked to take one picture that speaks about their challenges of being an IE teacher and to select one of the two for each team - one which depicted a key challenge. They recorded it on a sheet of paper and then shared it with the whole group. Their lists included issues such as exclusionary practices, lack of knowledge, skills needed to succeed, isolation in the workplace and teacher low self-esteem.

Freire (1977:62) promotes the idea that ' $[p]$ articipants, as they are increasingly posed with problems relating to themselves in the world and with the world, will feel increasingly obliged to respond to that challenge'. Thus, it was important to use a methodology that opens up a space for creative and imaginative possibilities as a group of participants who come together to delve deeply into an issue or problem that is relevant to their professional life world.

\section{Phase two}

The focus in this phase was talking more about the issues, and it opened up the opportunity to follow-up with the following prompt: What limits you the most within your inclusive classroom practices? They were asked to generate as many examples as possible and to jot them down. As a researcher, I wanted participants to be able to indicate which experience was the most pressing, and therefore asked each to stick a selfadhesive dot next to the one they thought most pressing and prompted them to generate solutions to address this experience.

\section{Phase three}

This phase focused on identifying and talking about the solutions. The teams were asked to do a poster presentation as an opportunity for collegial teams to reflect on the issues raised and to create a recommendation for action in the classroom.

\section{Data analysis}

The photographs taken during phase one were analysed drawing on the work of Wang and Burris (1997), who postulate that there are three ways to carry out analysis of the data when doing photovoice: selecting photographs, contextualising and codifying. Participants are brought together in a focus group to discuss a selection of the photos taken. Focus group techniques that incorporate photovoice have the unique advantage of being able to both contextualise the photographic data using the participants'own perspectives and codifying the data presented by each person by having the participants themselves identify common themes and concepts.

\section{Discussion of findings}

The findings supported a connection between a teaming approach and strengthening IE practice of pre- and inservice teachers. The following two themes emerged: enabling new professional learning to strengthen IE practice and selfreflection, which are discussed below.

\section{Enabling new professional learning to strengthen IE practice}

Violet, a student teacher, highlighted: 'When you honestly listen to someone, when you hear not only their words, but feel their experiences, and see the world through their eyes, one is changed'.

Professional learning can have a powerful effect on teacher skills and knowledge and on student learning if it is sustained over time. Professional learning focused on important content and is embedded in the work of professional learning communities that support ongoing improvements in teachers' practice (Darling-Hammond et al. 2009). Said Ivy, one of the preservice teachers: 'Teachers need to be thinking practitioners and learners must be valued as independent beings'. 
The teams highlighted that teaming enabled them to become aware of own and collective strengths of being an IE practitioner, create new learning opportunities about IE practice and create a safe space for reflection on IE practice.

Mezirow (1978) emphasises that when teachers are given the opportunity to work collaboratively with little intervention from facilitators, self-directed learning occurs. Student teacher Silver stated his views as follows: 'Our teaming initiative revealed answers, new perceptions and better understandings. As teams we did a lot of talking and thinking about what was important to us'.

Sharma (2010) notes that photovoice is an excellent means to initiate dialogue in a community setting. Teams used photo analysis as a tool and recognised how much they had already achieved and the depth of expertise that already existed amongst them (see photograph 2 as suggested by team 2 Figure 1).

Student teacher Zoe motivated her selection of this photograph stating:

... I became more conscious of the need to break out of the takenfor-granted single-subject, single-course, single-teacher pattern and embraces creative, innovative thinking and experimentation with others.

The participants expressed that they felt that their capacity increased, because they knew why they were doing what they did and exercised control and claimed ownership of best practices. Teacher Johanna highlighted: 'Now I am confident and better able to assist my learners for I know now what I am doing'.

Teacher Maria commented that the teaming process allowed them to: '... continuously construct and reconstruct, learn, (re)learnand (un)learn the meaning they attached to learning and create new and innovative ways to maintain it' (see photograph 4 [Figure 2] looking with a fresh set of eyes).

Teacher Suzanna highlighted her motivation for choosing this photograpgh: ... daily children enter the classroom with

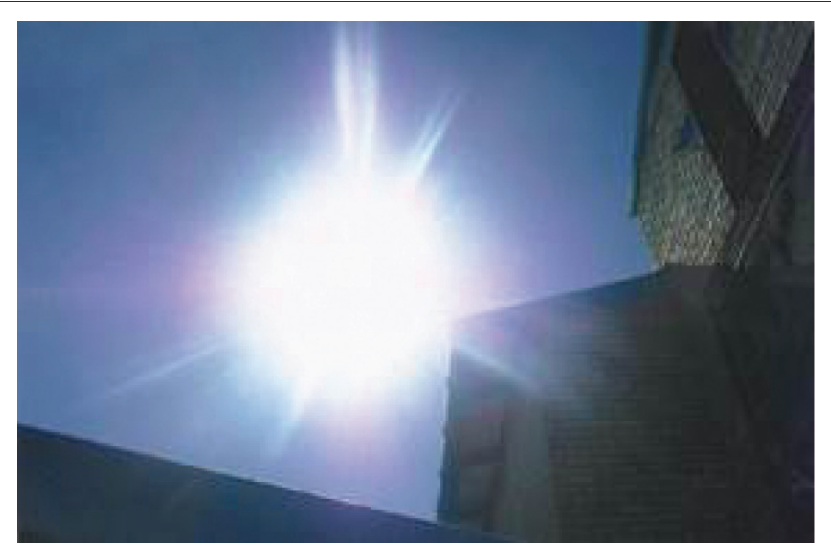

Source: Taken by team 2 .

FIGURE 1: Photograph 2 - 'I told you I can'. barriers to learning whilst as their teacher, I do not know how to create learning opportunities for them. I think of myself as: Teachers are incompetent professionals, semi-skilled individuals, filled with fear and rendered helpless by my low self-esteem.

Successful teaming breaks down the body of knowledge or skills to be learned into small, logically arranged and easily manageable parts, collectively within their teaching community. Teachers are able continually to learn to address the problems of practice they encounter and to meet the unpredictable learning needs of all of their students - and they take responsibility to contribute what they learn not only to their own practice but also to that of their colleagues (Darling-Hammond et al. 2005). According to Drago-Severson (2009:25), teaming creates an opportunity for adults to share their diverse perspectives and to learn about one another's ideas and assumptions, consider alternative perspectives and revise assumptions, in order to achieve growth.

The collegial teams in this study arrived somewhere, collectively, from an imagined past to an imaginative future of skills application through collaborative learning, which links directly to and supports the research objective to create a community of practice teams amongst FP teachers and student teachers, using teaming as a tool for developing and strengthening IE practices. Teachers were able to create, recreate and cocreate, through applying the principles of teaming, an infrastructure for learning composed of roles and responsibilities, inquiry, reflection and a focus on learners' learning. This concurs with the Department of Education (2006:17) National Policy Framework For Teacher Education and Development in South Africa:

... educators may require new skills in curriculum assessment of potential, curriculum differentiation, collaborative teaching and learning, collaborative planning and sharing reflection on practices and cooperation.

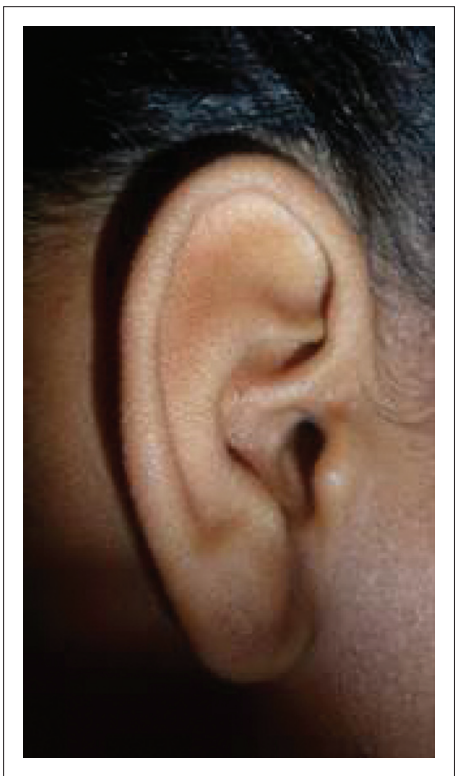

Source: Taken by team 1

FIGURE 2: Photograph 1 - 'This child I bring you'. 
Sammy, an inservice teacher, said:

'This programme increased my understanding of practice. I have learned so much about the latest educational ideas and practices, it is invigorating. I have a platform to share my successes as well as my challenges. I want to continue with my development and hone my skills to assist and accommodate my learners with barriers to learning'.

Shadow, a preservice teacher, reported:

'When we as a team did our planning for the coming week, a photograph collage of the challenges within our classroom was placed next to our planning schedule. This compelled us to be conscious of our classroom reality and to take action to improve on it in how we delivered the content'.

Teachers hold very little in the way of conversations and discussions on what is happening in their classrooms; therefore, they often conclude that very little learning takes place, because they cannot measure it against that of their colleagues' classrooms. Topping and Maloney (2005) state that inclusion is a dynamic process, not a static condition - a journey, not a destination. I want to go further and state that inclusion is learning, synonymous to professional learning.

\section{Self-reflection}

One of the things that all the participants referred to was the importance of teachers reflecting on their teaching practice from time to time. Reflective practice can affect professional growth and bring individuals to greater selfactualisation (Pedro 2006) through collaboration with others to apply knowledge and experiences into practice (Schön 1996). Dewey (1966:30-33), the father of reflective thinking, recommends:

- Open-mindedness, which is the active desire - through writing.

- To hear more than one side - reflection through dialogue.

- Whole-heartedness, which is willingness to throw yourself totally into an endeavor - reflection through helping and advising others.

- Responsibility as a form of integrity, a willingness to consider the consequences of possible changes and to go forward if they are consistent with your beliefs - reflection through decision making.

Collegial teaming as a professional growth process in its credo for reflective practice holds that everyone needs professional growth opportunities. As student Hayley stated:

Our team was able to build a community of enquiry that was able to move forward collectively with our practice through dialogical experiences that engage with key questions relevant to own practice.

Lawler (2003) maintains that not only is it important for teachers to reflect on their practice and critique their assumptions about learning, teaching and goals but it is also essential for those who design and implement these programmes to engage in critical questioning throughout programme implementation to assess effectiveness and enhance adult growth. Teacher Maroon mentioned as follows:
The reflective space has helped me to stay open and approach my work with more curiosity. I had felt quite stuck with some learners and also felt work was more routine and I was not enjoying what I was doing as much as I would have wanted.

Teacher Ivy revealed: 'The reflective space practice was a new experience in my practice and my initial responses were those of anxiety, fear of criticism, fear of invasion into my practice'.

Student Ruth said: 'I found the visual methodology to be really helpful as it develops another layer of reflection and support'.

Reflective practices enable teachers to learn and further develop the content and pedagogical knowledge, understandings and skills they need. Through reflection within collegial teams and revision of information and efforts, teachers and student teachers actively assess their personal impact on educational reform.

Drago-Severson (2009) identified the following collegial inquiry practices as highly effective and meaningful to teacher development: reflection through the process of writing, reflection through dialogue, reflection through decision making and reflection through helping and advising others. All these manifested in this study, as expressed by the participants individually and collectively.

\section{Conclusion}

At the beginning of the article, IE is positioned as the sole responsibility of teachers within their classrooms. Sarah, a teacher, highlighted: 'We are overwhelmed by feelings of negativity towards IE, because of their limited knowledge and skills to address it'.

From this came the research question: How can collegial teaming and photovoice as a tool promote the practice of IE in the FP?

The findings mostly concur with those reported in the literature, indicating that through a collegial teaming approach, accomplished teachers and student teachers accept responsibility for improving their practices. The implications of the research for teachers at school are that designing and facilitating learning experiences for pre- and inservice teachers necessitates innovative collaboration that is contextually situated, personally relevant and informed by authentic issues and experiences of IE practice (DarlingHammond et al. 2005). Most importantly, it is participatory, because it draws on the voices of all those who are involved in the research.

Supportive teams within school contexts need to be created for preservice teachers during work-integrated learning, to sustain their development and reflection in practice. Collegial teaming within the B.Ed. FP teacher education programme ensures continuity and integration 
between theory and practice - hence the need to develop both generic and specific competencies that will promote the practice of IE (Fleming et al. 2009). Under the guidance and support of mentor teachers, student teachers are able to merge experiences in the workplace with theory introduced at the institution, ensuring academic depth and rigour.

\section{Acknowledgements}

I would like to acknowledge Professor Naydene de Lange, who availed herself as a critical reader of this article, and I appreciate the commitment and knowledge she brings to participatory research methodology.

\section{Competing interests}

The author declares that she has no financial or personal relationships, which may have inappropriately influenced her in writing this article.

\section{References}

Ainscow, M., 2002, 'Using research to encourage the development of inclusive practices', in P. Farrell \& M. Ainscow (eds.), Making special education inclusive, pp. 295-308, David Fulton, London.

Artiles, A.J., 2003, 'Special education's changing identity: Paradoxes and dilemmas in views of culture and space', Harvard Educational Review 73, 164-202.

Arzubiaga, A., Artiles, A.J., King, K. \& Harris-Murri, N., 2008, 'Beyond research on cultural minorities: Challenges and implications of research as situated cultural practice', Exceptional Children 74, 309-327.

Blackbeard, D. \& Lindegger, G., 2014, 'The value of participatory visual methods in young masculinity research', Procedia - Social and Behavioral Sciences 165 $85-93$.

Booth, T. \& Booth, W., 2003, 'In the Frame: Photovoice andmothers with learning difficulties', Disability \& Society 18(4), 431-442.

Charmaz, K., 2006, Constructing grounded theory: A practical guide through qualitative analysis, Sage, Los Angeles.

Cohen, L., Manion, L. \& Morrison, K., 2007, Research methods in education, 6th edn. Routledge-Falmer, London.

Cortazzi, M. \& Jin, L., 2007, 'Narrative learning, EAL and metacognitive development', Early Child Development and Care 177(6\&7), 645-660.

Darling-Hammond, L., Bransford, J., LePage, P., Hammerness, K. \& Duffy, H., 2005 Preparing teachers for a changing world: What teachers should learn and be able to do, Jossey-Bass, San Francisco.

Darling-Hammond, L., Chung Wei, R., Andree, A. Richardson, N. \& Orphanos, S. 2009, Professional learning in the learning profession: A status report on teacher
development in the United States and abroad, Stanford University, National Staff development in the United States and abroad, Stanford Univ
Development Council and The School Redesign Network.

De Lange, N., Mitchell, C. \& Stuart, J. (eds.), 2007, Putting people in the picture: Visual Methodologies for social change, Sense, Rotterdam.

Department of Basic Education, 2012, Inclusive education; integrated quality management systems, Department of Education, Pretoria.

Department of Education, 2001, Education White Paper 6. Special needs education: Building an inclusive education and training system, Government Printers, Pretoria.

Department of Education, 2006, National policy framework for teacher education and development in South Africa, Department of Education, Pretoria.

Dewey, J., 1966, Democracy and education, Free Press, New York.

Dixon, M. \& Hadjialexiou, M., 2005, 'Photovoice: Promising practice in engaging young people who are homeless', Youth Studies Australia 24(2), 52-56.

Drago-Severson, E., 2004, Helping teachers learn. Principal leadership for adult growth and development, Sage, Thousand Oaks.

Drago-Severson, E., 2009, Leading adult learning. Supporting adult development in our schools, Sage, Thousand Oaks.
Dumbrill, G., 2009, 'Your policies, our children: Messages from refugee parents to child welfare workers and policymakers', Child Welfare 88(3), 145-168.

Engelbrecht, P. \& Green, L., 2007, Responding to the challenges of inclusive education in South Africa, Van Schaik, Pretoria.

Fleming, J., Martin, A.J., Hughes, H. \& Zinn, C., 2009, 'Maximizing work-integrated learning experiences through identifying graduate competencies for employability: A case study of sport studies in higher education', The Asia-Pacific Journal of Cooperative Education 10(3), 189-201.

Freire, P., 1973, Education for critical consciousness, The Continuun Publishing Company, New York.

Freire, P., 1977, Pedagogy of the oppressed, Penguin Group, London.

Freire, P., 1992, Pedagogy of the oppressed, Continuum, New York.

Freire, P., 2000, Cultural action for freedom (Harvard Educational Review: Monograph Series No. 1, revised edition), Harvard Educational Review, Cambridge.

Gallo, M., 2001, 'Immigrant workers' journeys through a new culture: Exploring the transformative learning possibilities of photography', Studies in the Education of Adults 33(2), 109-117.

Gamble, E., 2006, A practical guide to photovoice, Prairie Women's Health Centre of Excellence, Winnipeg.

Geduld, D., 2009, 'The role of school management teams in the implementation and maintenance of inclusive education', Unpublished M.Ed dissertation, Nelson Mandela Metropolitan University, Port Elizabeth.

Jurkowski, J., 2008, 'Photovoice as participatory action research tool for engaging people with intellectual disabilities in research and program development', Intellectual and Development Disabilities 46(1), 1-11.

Kelchterman, G., 2006, 'Teacher collaboration and collegiality as workplace conditions', Zeitschrift fur Padagogik 52(2), 1-7.

Lawler, P.A., 2003., 'Teachers as adult learners: A new perspective', in K.P. King \& P.A. Lawler (eds.), New directions for adult and continuing education, Jossey-Bass, San Francisco.

Mezirow, J., 1978, Perspective transformation, Adult Education, Jossey-Bass, San Francisco.

Mitchell, C., 2011, Doing visual research, Sage, London.

Moletsane, R., De Lange, N., Mitchell, C., Stuart, J., Buthelezi, T. \& Taylor, M., 2007, 'Photo voice as an analytical and activist tool in the fight against hiv and aids stigma in a rural KwaZulu-Natal School', South African Journal of Child and Adolescent Mental Health 19(1), 19-28

Moletsane, R., Mitchell, C., Smith, A. \& Chisholm, L., 2008, Methodologies for mapping a Southern African girlhood, Sense, Rotterdam.

Novak, J., 2008, 'Inviting passionate educational leadership', in B. Davies \& T. Brighouse (eds.), Passionate leadership in education, pp. 35-57, Sage, London. http://dx.doi. org/10.4135/9781446216675.n3

Patton, M., 2002, Qualitative research \& evaluation methods, Sage, London.

Pedro, J., 2006, 'Taking reflection into the real world of teaching', Kappa Delta $P i$ Record 42(3), 129-133.

Robertson, J., 2008, Coaching educational leadership. Building leadership capacity through partnership, Sage, London.

Ruijs, N., Van der Veen, I. \& Peetsma, T., 2010, 'Inclusive education and students without special educational needs', Educational Research, 52(4), 351-390.

Schön, D., 1987, Educating the reflective practitioner, Jossey-Bass, San Francisco.

Schön, D.A., 1996, Educating the reflective practitioner: Toward a new design for teaching and learning in the professions, Jossey-Bass, San Francisco.

Senge, P.M., Kleiner, A., Roberts, C., Ross, R.B. \& Smith, B.J., 1994, The fifth discipline fieldbook, Doubleday, New York.

Shah, M., 2011, 'The dimensionality of teacher collegiality and the development of teacher collegiality scale', International Journal of Education 3(2), 322-333.

Sharma, M., 2010, 'Photovoice in alcohol and drug education', Journal of Alcohol and Drug Education 54(1), 3-6.

Sheehy, K, Rix, J., Collins, J., Hall, K., Nind, M. \& Wearmouth, J., 2009, 'A systematic review of whole class, subject-based pedagogies with reported outcomes for the academic and social inclusion of pupils with special educational needs', in Research Evidence in Education Library, EPPI-Centre, Social Science Research Unit, Institute of Education, University of London, London.

Topping, K. \& Maloney, S., 2005, The RoutledgeFalmer reader in inclusive education, RoutledgeFalmer, London.

Waitoller, F. \& Kozleski, E., 2008, 'Teacher learning for inclusive education: Inclusive professional learning schools', Review of Research in Education 22(2), 1-31.

Wang, C. \& Burris, M., 1997, 'Photovoice: Concept, methodology, and use for participatory needs assessment', Health Education \& Behavior 24(3), 369-387.

Wang, C., Burris, M. \& Xiang, Y., 1996, 'Chinese village women as visual anthropologists: A participatory approach to reaching policymakers', Social Science \& Medicine 42(10), 1391-1400.

Wang, C., Yi, W., Tao, Z. \& Carovano, K., 1998, 'Photovoice as a participatory health promotion strategy', Health Promotional International 13(1), 75-86. 